\title{
Medical Value as a New Strategy to Increase Corporate Viability: Market Chances and Limitations in the Diagnostic Industry
}

\section{Schäfer H Hendrik , Filser Ludwig ${ }^{2}$, Rohr Ulrich P $^{1}$, Laubender Ruediger $\mathbf{P}^{2}$, Dieterle Thomas ${ }^{1}$, Maitland Roger ${ }^{3}$ and Zaugg Christian $E^{4}$}

${ }^{1}$ Divisional Medical and Scientific Affairs, F. Hoffmann-La Roche Ltd, 4070 Basel, Switzerland

${ }^{2}$ Roche Professional Diagnostics, Biostatistics and Data Management, 82377 Penzberg, Germany

${ }^{3}$ Graduate School of Business, University of Cape Town, 8002 Cape Town, South Africa

${ }^{4}$ Roche Professional Diagnostics, Global Medical and Scientific Affairs, 6343 Rotkreuz, Switzerland

\begin{abstract}
Study background: While the strategic advantage of Medical Value (MV) products is widely accepted in developed markets, it remains unclear if varying societal wealth influences the perception of customers on MV products.

Methods: 231 of 240 Internal Medicine physicians from 8 countries participated in a survey with 5 multiple choice questions on MV. Responses from countries have been allocated to income levels according to world-bank data. Three groups have been defined (high-income countries: Canada, Norway and Switzerland=developed markets, upper-mid income markets: Argentina, China, Mexico and Turkey, lower-mid income counties: India=emerging markets). Answers have been statistically analyzed in subgroups (emerging markets vs. developed markets).

Results: The majority of physicians believed that reliable and clinically validated treatment algorithms should accompany a product qualifying for MV. Algorithms should be created, predominantly for existing markers. Emphasis has been given to the discovery of better markers for well-known diseases in developed markets. Physicians 'answers on pivotal factors for MV products yielded highest emphasis for generalizability (global technical standardization and data comparability). Technical excellence was given lower priority in developed markets comparing to emerging markets. Cost control was emphasized mainly in high-income markets.
\end{abstract}

Conclusion: Both developed and emerging markets demand more clinical trials to establish algorithms for diagnostic tests. The prove of clinical utility is a pivotal factor for sustainable business success.

Keywords: Medical value; Diagnostic industry; Corporate viability; Societal value; Health care; Cost-control

\section{Introduction}

\section{Innovation requires non-transferrable solutions}

In the last five years the diagnostic industry is facing stricter regulatory hurdles for product approval [1]. In addition, the competition for customers, and market segments has grown remarkably. Because competition leads to product substitutability and to price erosion [2] diagnostic vendors try to outperform competitors with highthroughput volume of diagnostic devices, technical improvement of their assays and high-level customer support.

Although, environmental factors force businesses to constantly innovate [3], related costs are high and executives become increasingly risk averse [4]. Current management literature describes a negative relationship between competition and innovation [5]. Other authors state an inverse U-curve relationship between these two determinants [6]. Competitive pressure seems to result in an initial increase in innovation, but a decline can be observed in the long run. Facing competition, the inclining part of the inverse $\mathrm{U}$-shape can be explained by the attempt of companies to explore alternative business models [7]. This "escape phenomenon" creates a momentum for companies to innovate and to develop non-transferrable solutions, which allow them to quickly gain high market shares.

\section{A changing environment requires new value-based thinking}

In recent years diagnostic companies have realized that the simple service provision based on high volume test devices, that target testing efficiency and accuracy, might not be sufficient anymore to maintain annual growth rates. This is based on a changing landscape of payer policies resulting from monetary constrains in developed markets
(DM) and emerging markets (EM) [8]. Especially notable is a tendency of health care systems to change from service-based towards valuebased reimbursement, which emphasizes the payer's need for more effective patient management (Figure 1).

Multiple theoretical articles elucidate the related concept of "customer value" in service delivery [9]. While this concept certainly holds true for pharmaceutical agents, the reimbursement of diagnostic tests is still driven by the technology used and not by the value it creates [10].

Different to this, for pharmaceutical agents, the National Institute for Health Care Excellence (NICE) has targeted the cost-intensive approach of service reward several years ago by introducing strict evidence-based medicine and outcome-based reimbursement of physicians, e.g. in hypertension [11]. Also in Germany, in 2011 the AMNOG (Act on the Restructuring of the pharmaceutical market) has changed the landscape of reimbursement. The legislation became necessary as the expenditure for drugs have increased dramatically by 1.5 billion $€$ in 2009 (5.3\%). AMNOG was created to sustain a new balance between innovation and affordable medicines [12].

*Corresponding author: Schäfer $\mathrm{H}$ Hendrik, Divisional Medical and Scientific Affairs, F. Hoffmann-La Roche Ltd, 4070 Basel, Switzerland, Tel: + (41) 6168711 62; Fax: + (41) 6168889 63; E-mail: Hendrik.Schaefer@roche.com

Recieved January 23, 2015; Accepted February 28, 2015; Published March 10, 2015

Citation: Schäfer H Hendrik, Filser Ludwig, Rohr Ulrich P, Laubender Ruediger P, Dieterle Thomas, Maitland Roger, Zaugg Christian E (2015) Medical Value as a New Strategy to Increase Corporate Viability: Market Chances and Limitations in the Diagnostic Industry. J Entrepren Organiz Manag 4: 131. doi:10.4172/2169026X.1000131

Copyright: (C) 2015 Schäfer H Hendrik, et al. This is an open-access article distributed under the terms of the Creative Commons Attribution License, which permits unrestricted use, distribution, and reproduction in any medium, provided the original author and source are credited. 

Value as a New Strategy to Increase Corporate Viability: Market Chances and Limitations in the Diagnostic Industry. J Entrepren Organiz Manag 4: 131. doi:10.4172/2169-026X.1000131

Page 2 of 8

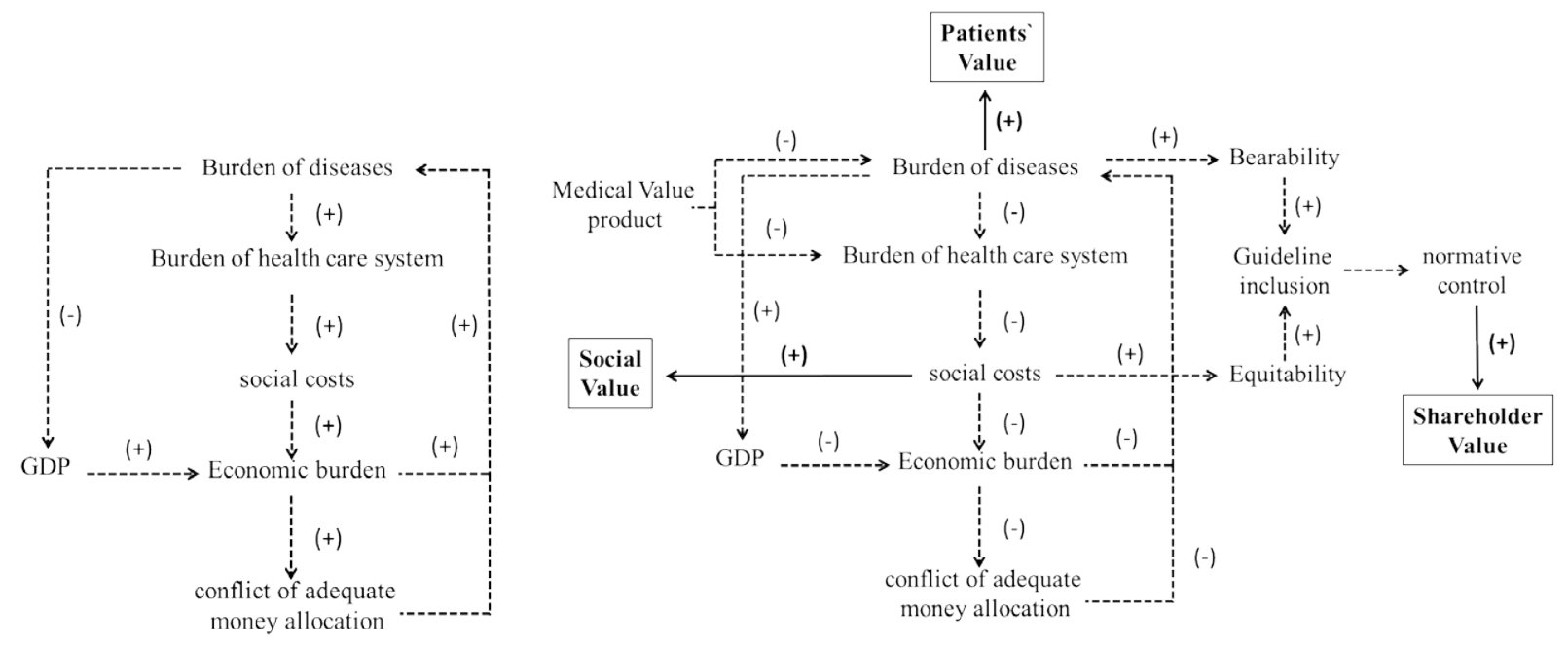

A

B

Figure 1: A: Causal-Loop diagram displaying the relationship between disease burden and economic burden. B: Triple Value generation with innovative MV products.

According to the new legislation the manufacturer now is required to submit evidence of the added value for the patient. The Federal Joint Committee decides whether and what additional benefits a new drug has and how this will be reflected in the pricing. For medical products, prices are negotiated on the basis of the evaluation of the added value. For drugs with no additional benefit a fixed amount is set. The new law aims to create savings of about 2 billion $€$ per year. AMNOG is planned to be extended to medical devices. More systems are likely to change and will prospectively base their policies on reliable cost-effectiveness data [13] to lower economic and social costs. Figure 1 displays how Medical Value products reduce social costs. Their contribution to the society may result into Guideline inclusion and increase bearability and equitability. Normative control yields profit for shareholders Figure 1.

\section{The effectiveness of health systems differs}

Interestingly, healthcare spending and Disability Adjusted Life Years (DALYs) follow an exponential function. Figure 2 displays the different effectiveness of the 8 health care systems, which are in focus in this paper. Whilst Norway, for example, at the steep part of the DALY-healthcare spending grid, has one of the highest expenditures in the world, their accumulated DALYs in 2012 are only marginally higher than those of Canada, whose per capita healthcare spending is 3000 USD lower. Vice versa, in the middle part of the curve a moderate increase in healthcare spending translates into a considerable decline of DALYs [14].

Interventions that prove to reduce DALYs have a high potential to preserve or even release financial resources. Such resources can be reinvested in the health care system to stabilize it further and to improve patient's lives. Figure 2 implicates that higher cost per capita do not necessarily translate to better healthcare. Theoretically, health care systems that may range at the right upper corner of the pictogram are likely to profit most from diagnostic tests that release financial resources.

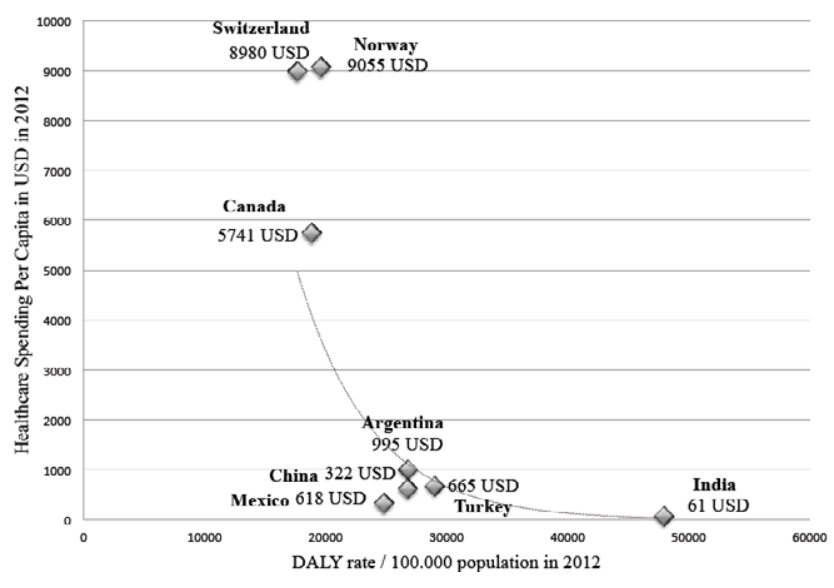

Figure 2: Correlation between costs per capita on healthcare [15] and Burden of Disease (in DALY).

\section{Targeting social costs becomes an important argument} for payers

Social costs express the expense to an entire society resulting from a defined event, an activity or a change in policy. More tangibly, they reflect the amount of Years Life Lost (YLL) and Years Lived with Disability (YLD). On the other side, economic costs portray productivity losses (which were first introduced in the "Value of lost output model" [16] by the WHO) as well as direct health care costs, impacting a society`s total GDP.

While pharmaceutical companies have implemented a dual concept of targeting a) physicians and b) payers simultaneously by running both, clinical and health economic trials, the diagnostic industry has only marginally adopted this thinking in their market access approaches.

For many years the registration of diagnostic tests in the 
Citation: Schäfer H Hendrik, Filser Ludwig, Rohr Ulrich P, Laubender Ruediger P, Dieterle Thomas, Maitland Roger, Zaugg Christian E (2015) Medical Value as a New Strategy to Increase Corporate Viability: Market Chances and Limitations in the Diagnostic Industry. J Entrepren Organiz Manag 4: 131. doi:10.4172/2169-026X.1000131

Page 3 of 8

European Union only required the $C \epsilon$ label, however in the light of financial shortcuts, more and more health authorities request a proof, that diagnostic tests not only have reasonable pricing but also add considerable value to the society [17]. With the $(\epsilon$ marking, the manufacturer declares "that the product meets the applicable requirements according to EU Regulation 765/2008 for its affixing."

\section{Medical value}

Since more than a decade the question how Value in Health care can be measured has been discussed controversially; however there is agreement on the overarching concept of assessing health outcomes achieved per dollar spent [18]. Thus, the "value"- term arises around patients and payers simultaneously describing a framework for performance improvement in health care [19].

Roche Diagnostics has introduced the term Medical Value in their corporate language to differentiate products of the mature product portfolio from products with innovative character. Novel products with MV follow a stringent definition and must:

1) Improved patient outcome that is derived through diagnostic tests and algorithms, validated in clinical utility studies.

2) Deliver actionable and medically relevant information enabling support and guidance in decision-making and justifying the change of the current disease management by addressing a currently unmet medical need.

Diagnostic tests with MV can help to improve patient management and reduce direct and indirect health care costs. However, to prove a potential benefit for payers, clinical evidence must be created [20]. In this respect, randomized controlled trials and meta-analyses are credible tools to validate a diagnostic concept [21] while providing the highest levels of evidence. MV is added, when e.g. a test allows patient stratification into responders/non-responders for a given medical treatment or allows a more efficient/more effective allocation of patients to a certain treatment or disease management.

\section{Medical value translates to societal value}

MV creates benefits for patients, the society and ultimately for shareholders (Figure 1B). Hitherto the separation of product development and evidence generation for product utility was a wellaccepted axiom in the diagnostic industry. Often it took a considerable amount of years until the medical community had accepted and incorporated a diagnostic test into the clinical practice. Creatinine for example, discovered by Max von Pettenkofer (1818-1901), developed its value as a marker for impaired kidney function only over time and required more than 160 years until its use has been recommended in clinical guidelines. While "outsourcing" of clinical studies to the society was a "low-cost" approach for vendors, it often implied increased social costs (AUC [Area under the curve] Figure 3A). Social costs arise due to false clinical decision making and have to be carried by all stakeholders involved in healthcare (patients, payers, physicians, society).

\section{Technical product improvement not always translate into medical value, for patients or physicians}

When the first high sensitivity troponin T assay had been introduced, the technical improvement created a high level of confusion amongst the medical community. Suddenly more patients without myocardial infarction turned out to be troponin-positive on the basis of conditions other than myocardial infarction [22]. Thus, experts have created the term "troponitis" referring to a limited usefulness of positive test- results. In the absence of harmonized recommendations that clearly indicated under which conditions a patient could be sent home safely, more confirmatory tests had to be performed and, physicians' triage decisions got more individualized, guided by risk perception [23] or fear of malpractice [24]. The troponin example demonstrates the risk for over-utilizing health care costs [25], caused by unnecessary interventions through more false-positive results [26].

While the financial attractiveness for vendors to leave "evidence creation" to the society has been clearly outlined, this traditional approach also yields downsides for companies:

Patent protection often expires until the value of a diagnostic parameter has been completely understood by physicians and until a given marker has made its way in clinical guidelines. This leads to lower revenue creation and slow market uptakes until the level of knowledge and the limitations are assessed [27]. Figure 3 displays the classical device development (A) and the development of a MV product (B).

In the described troponin example, the reluctance of physicians to use the test forced companies to readjust and to establish algorithms allowing early rule out of patient without myocardial infarction [28]. The acceptance of the assay remarkably increased, along with customer's trust in the innovation.

The "MV approach" (Figure 3B) provides a "product" and a "product's manual" but clearly creates more costs for the vendor. Nevertheless, early evidence creation implies advantages for patients, the society (AUC Figure 3B < AUC Figure $3 \mathrm{~A}$ ) and, in the long-run for shareholders. (Figure 1). However, in diagnostics, appropriate reimbursement does not follow the magnitude of innovation yet [10].

\section{Is medical value a concept applicable in all markets?}

While the concept of reducing societal costs is desirable in developed markets, it remains elusive if a MV strategy is appropriate for emerging markets and to what extend customers will base their purchase decision on clinically validated diagnostic algorithms. This study has been undertaken to better understand customer-perception of MV depending on the socio-economic context. Uncertainty remains, particularly in EM, whether financial aspects and general access to diagnostics is more important than the improvement of the current medical "gold standard".

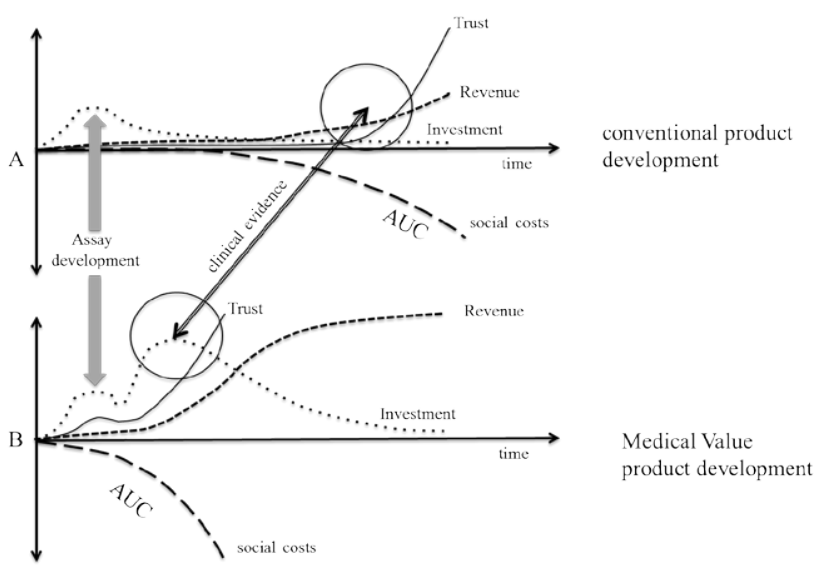

Figure 3: Creation of clinical evidence and its consequence regarding revenue, investment, customer`s trust and social costs. 
Citation: Schäfer H Hendrik, Filser Ludwig, Rohr Ulrich P, Laubender Ruediger P, Dieterle Thomas, Maitland Roger, Zaugg Christian E (2015) Medical Value as a New Strategy to Increase Corporate Viability: Market Chances and Limitations in the Diagnostic Industry. J Entrepren Organiz Manag 4: 131. doi:10.4172/2169-026X.1000131

Page 4 of 8

In this light, it needs to be investigated whether restrained access to treatment options or their total absence limits the value or even governs the rejection of such products. Ultimately it needs to be understood if the perception of higher net-benefit for society justifies higher prices for MV products in these markets

\section{Methods}

Five key-questions have been designed in a multiple-choice manner. These questions target the view of physicians $(\mathrm{N}=240)$ on the development of the health system (Q1, Table 1) and on the definition and how the term "gold standard" is conceptualized in different health care systems $(\mathrm{Q} 2$, Table 1). We investigated what the customer associates with the term "Medical Value" in the context of their health care environment, targeting prospective product features that could potentially perceived as "value adding" (Q3, Table 1). Based on this we assessed which aspect of a MV product is seen as the most pivotal factor that would guide a purchase decision (Q4, Table 1). To understand customer's expectations we finally investigated which areas the diagnostic industry should invest more, targeting prospective product strategies (Q5, Table 1).

The survey has been executed by Genentech, California, USA using an anonymized internet-based crowd-sourcing tool (SERMO), hosted by World One, Boston, USA. SERMO is a shared service, allowing multiple companies to gain quick and comprehensive insights on conceptual questions. Invitations to participate in this cross-sectional survey have been sent out to 240 Internal Medicine physicians in 8 different countries (Figure 4). A monetary compensation has been paid to attending physicians.

To assess differences in customer expectations, responses from countries have been allocated to income levels according to worldbank data (atlas method) 2013.

Three groups have been defined as follows: Canada, Norway and Switzerland [N=77] qualified as high-income countries with a

\section{Survey Questions}

From your country/region perspective what do you think will be the future of the health system in the next 10-15 years? Select the most appropriate answer.

- A 2-class Medicine (or a private-public sector) scenario is most likely. Products will be successful, that continue to improve the standard of treatment in the private sector regardless of the price. In the public sector price matters. Cheap products will succeed that meet the current gold standard.

- The whole society must profit from solutions that are better than the current gold standard. Reimbursement will continue for new innovative test. To compensate for higher costs, governments will ask for flat pricing of standard tests.

- There will be no regulation and mandatory health insurance.

- Government will shift the focus on primary prevention and will foster the reimbursement of screening, vaccination and risk-stratification rather than treatment, where all people will receive the standard care.

- Stricter monitoring of citizens and their health behavior is the solution for cost control. Reimbursement will be performed according to patient $\mathbf{s}$ compliance/ behavior.

Depending on your particular context (regional/cultural) what do you think is the most appropriate interpretation of the term "gold standard"? Select the most appropriate answer.

- Gold standard is a well-defined term without room for interpretation and refers to a guideline-based and generally accepted standard that is defined to treat/ diagnose a disease.

- For me (in my view) "gold standard" refers to the highest standard (regarding treatment/cure) that my health system is able to afford.

- For me (in my view) "gold standard" is the equitable access of all patients to basic but well-performing diagnostic tools all over the world regardless of their social heritage.

What do you associate with the term „Medical Value“ in diagnostics? Select the most appropriate answer.

- Providing cheapest diagnostic/therapeutic option according to gold-standard (Emphasis on cost-control)

- Providing diagnostic/therapeutic solutions, better than current gold-standard at the monetary expenses required for innovation (Emphasis on innovation)

- Providing a specific service that accompanies a diagnostic/therapeutic option (reliable treatment and diagnostic algorithms, validated in clinical trials that may shorten time to diagnosis and or treatment and simplify diagnosis/treatment (Emphasis on service)

- Maximize technical preciseness (Emphasis on technical excellence)

- $\quad$ Providing highest quantity of diagnostic tests (Emphasis on variety)

When creating a "medical value product" multiple factors must be taken into consideration. It is unlikely that a product will be able to meet all aspects. What do you think is the most pivotal factor?

- Generalizability (global technical standardization and data compatibility)

- $\quad$ Non/Minimal-Invasiveness

- Release of health-care resources (through faster processes/algorithms)

- $\quad$ Price of test/equipment

- General accessibility/Mobility of the device

What do you think is the area in which the diagnostic industry should invest more? Select the most appropriate answer.

- Establishment of treatment algorithms that help to maximize the diagnostic value of existing markers to reliably guide physicians in the diagnosis of patients in their daily practice.

- Discovery of new/better diagnostic markers for well-known diseases.

- Discovery of new markers for orphan/neglected disease areas.

- Development of electronic devices to improve processing/distribution of data (Apps, handhelds, devices for self-management).

- Investment in companion-diagnostics (development of diagnostic markers and corresponding drugs) that allow a reliable tracking of therapy success.

Table 1: Survey Questions. 
Citation: Schäfer H Hendrik, Filser Ludwig, Rohr Ulrich P, Laubender Ruediger P, Dieterle Thomas, Maitland Roger, Zaugg Christian E (2015) Medical Value as a New Strategy to Increase Corporate Viability: Market Chances and Limitations in the Diagnostic Industry. J Entrepren Organiz Manag 4: 131. doi:10.4172/2169-026X.1000131

Page 5 of 8

gross national income per capita of 12,746 USD or more. The US has been purposely excluded from this investigation due to the ongoing implementation of the Patient Protection and Affordable Care Act. Current structural change implies the possibility of biased answers. Argentina, China, Mexico and Turkey [N=74] were allocated to the group of upper-mid income countries with a gross national income per capita between 4,126 to 12,745 USD.

India $[\mathrm{N}=80]$ has been chosen for a representative for lower-mid income countries with a gross national income per capita between 1,046 to 4,125 USD. Low-income countries have not been included due to the unavailability in SERMO.

High-income countries have been defined as DM while lower-mid income countries and upper-mid income countries have been allocated to the group of EM.

Answers have been collected by SERMO and were statistically analyzed using R 3.0.1 (R Foundation for Statistical Computing, Vienna, Austria) by Roche Professional Diagnostics, Biostatistics and Data Management in Penzberg, Germany. For each question, the physician could only pick one response option. Thus, for each question, a table with response options stratified by EM and SM were constructed. For such a table, frequencies for each response option and corresponding proportions (frequencies divided by the corresponding numbers of doctors) have been calculated.

The difference $(\Delta)$ of the proportions between the two groups (EM and DM) was assessed for each response option and a p-value based on a two-sided $\mathrm{z}$-test for that difference of proportions has been established. P-values as a measure of evidence against the null hypothesis were simply reported from these tests instead of performing statistical hypothesis tests at a multiplicity-adjusted, predetermined level of statistical significance.

\section{Results}

231 out of possible 240 Internal Medicine physicians responded to the survey, of which $\mathrm{N}=77$ physicians originated from high-income countries (developed Markets), $\mathrm{N}=74$ from upper-mid income countries and $\mathrm{N}=80$ from lower-mid income countries thus $\mathrm{N}=154$ physicians originated from emerging Markets.

\section{The future of the health care systems}

$33.8 \%(\mathrm{~N}=78$ out of 231$)$ of all doctors foresaw a two-class Medicine scenario with high prices for innovative products accompanied with premium prices in the private (first class) sector and cost centered products according to gold standard in the public (second-class) sector.

Similar proportions in EM $(32.5 \%, \mathrm{~N}=50$ out of 154$)$ and DM (36.4\%, N=28 out of 77) could be observed. Physicians in the EM (14.3\%, $\mathrm{N}=22$ out of 154$)$ rather predict a future health care system without regulation and mandatory health insurance than their colleagues in DM $(2.6 \%, \mathrm{~N}=2$ out of 77$)$ with $\Delta=11.7 \%(\mathrm{p}=0.0005)$.

The second most frequently chosen answer in both markets was that a whole society should profit from more expensive but innovative markers. More physicians from DM compared to EM (30\%, N=23 and $24 \%, \mathrm{~N}=37$ in $\mathrm{EM}, \Delta=5.8 \%, \mathrm{p}=0.35)$ believed that the whole society must profit from solutions exceeding the current gold-standard and that the health care system will continue to reimburse new innovative tests. However, to compensate for higher costs, governments will ask for flat pricing of standard tests.

Fairly comparative results for both markets have been gathered for the future focus on primary prevention ( $14.3 \%$ for both markets). This also held true (EM $14.9 \%, \mathrm{~N}=23$ out of $154, \mathrm{SM} 16.9 \%, \mathrm{~N}=13$ out of 77) for a stricter monitoring of citizens and their health behavior (as a solution for cost control in a sense that reimbursement for treatment will be performed according to patient's compliance and behavior). In this scenario diagnostics will play a pivotal role for monitoring disease prevention and cost-control.

Conclusion: Physicians anticipate either a future 2-class medicine in which innovative products are affordable only in the private (first class) sector or a health care system in which the costs of innovative products are hedged by flat pricing of non-MV products.

\section{“Gold-standard" is subjective to the environment}

Overall, $55.0 \%(\mathrm{~N}=127$ out of 231$)$ of physicians relate to the generally accepted definition of "guideline-based standards in treating and diagnosing a disease", however, differences were observed between the markets. $63.6 \%(\mathrm{~N}=49$ out of 77$)$ of DM-physicians, but only $50.6 \%$ $(\mathrm{N}=78$ out of 154$)$ of physicians in the EM agreed on this. About $25 \%$ of all physicians believe that "Gold Standard" refers to the highest standard that a health system is able to afford. Surprisingly there was only a marginal difference between DM and EM (22.1\%, N=17 out of 77 in $\mathrm{SM}, 26.6 \%, \mathrm{~N}=41$ out of 154 in $\mathrm{EM}) .8 .4 \%$ ( $\mathrm{p}=0.11$ ) more physicians from EM (22.7\%, N=35 out of 154) than from SM (14.3\%, N=11 out of 77) believed that the term "Gold Standard" refers to the equitable access of all patients to basic but well-performing tools regardless of their social heritage.

Conclusion: The term Gold standard is interpreted differently in EM and DM.

Both markets mainly adhere to the believe that "gold standard" is a term used to describe a method/procedure that is widely recognized as the best available. A main concern of EM is the equitable access of all patients to well-performing diagnostic tools, which seems less relevant in DM.

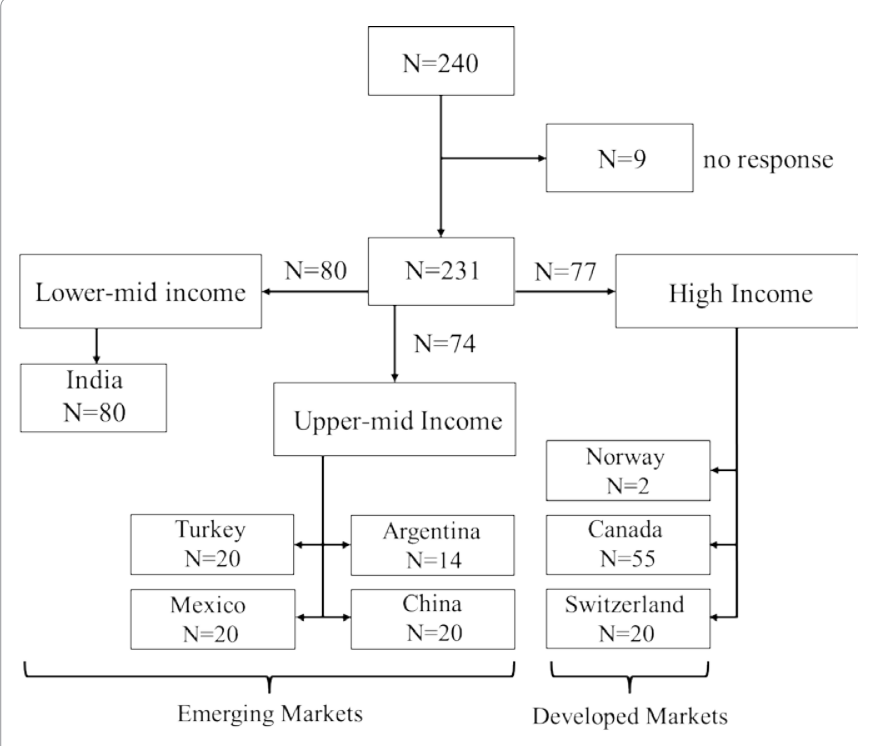

Figure 4: Origin and Inclusion of physicians in SERMO 
Citation: Schäfer H Hendrik, Filser Ludwig, Rohr Ulrich P, Laubender Ruediger P, Dieterle Thomas, Maitland Roger, Zaugg Christian E (2015) Medical Value as a New Strategy to Increase Corporate Viability: Market Chances and Limitations in the Diagnostic Industry. J Entrepren Organiz Manag 4: 131. doi:10.4172/2169-026X.1000131

Page 6 of 8

\section{Cost-control and reduced emphasis on technical excellence indicates a paradigm change in the health care system of saturated with developed markets}

$37.2 \%$ of all physicians ( $\mathrm{N}=86$ out of 231 ) believed that diagnostic tests should be accompanied by reliable and validated treatment algorithms to qualify for a Medical Value product (Figure 5). This was true for both, DM $(42.9 \%, \mathrm{~N}=33$ out of 77$)$ and $\mathrm{EM}(34.4 \%, \mathrm{~N}=53$ out of 154).

Low emphasis has been given to technical excellence and maximal technical accuracy in $\mathrm{DM}(2.6 \%, \mathrm{~N}=2$ out of 77$)$ comparing to $13.0 \%$, $\mathrm{N}=20$ out of 154 in EM with $\Delta=10.4 \%(\mathrm{p}=0.001)$.

Providing the most cost-effective diagnostic/therapeutic option according to the level of the current gold standard in the light of cost control was surprisingly more strongly emphasized in DM $(29.9 \%$, $\mathrm{N}=23$ out of 77$)$. Fewer physicians $(16.2 \%, \mathrm{~N}=25$ out of 154$)$ were concerned about this aspect in $\operatorname{EM}(\Delta=13.6 \%$ with $\mathrm{p}=0.023)$ (Figure 5$)$.

Conclusion: Treatment algorithms is highly desirable in both markets. Fewer physicians are concerned about technical excellence in DM comparing to EM. In DM more emphasis was given to cost control comparing to EM. Both findings indicate a need for high-volume solutions in EM and for more cost-effective MV solutions in DM.

\section{Data generalizability and comparability as a feature of medical value products}

The majority $(\mathrm{N}=85)$ of all surveyed physicians believed that global technical standardization and data comparability is an important additional factor for a MV product $(\mathrm{N}=27 ; 35 \%$ in $\mathrm{SM}, \mathrm{N}=58 ; 38 \%$ in EM). The release of heath care resources appeared less relevant. The difference between DM and EM was statistically not significant $(\mathrm{N}=18$; $23 \%$ in SM, N=28; $18 \%$ in DM). This also held true for the remaining factors, general accessibility/mobility of the device, and minimal invasiveness.

Key message: There is a high demand for inter-assay comparability and technical standardization in both, DM and EM. Of note, the impact of MV products on the society (release of health care resources) has given rather low emphasis in both markets.

\section{Emerging and developed Markets demand clinical evidence through validated treatment algorithms}

Regarding future product strategy, the majority of all physicians believe that treatment algorithms should be created, predominantly for

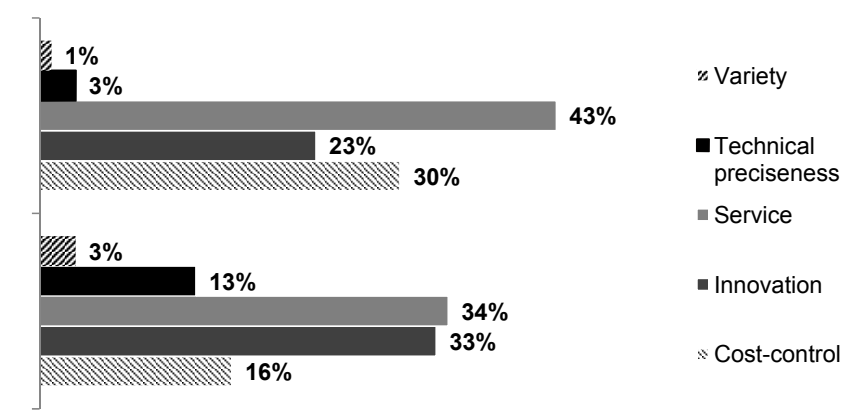

*Service refers to the generation of treatment algorithms

Figure 5: Comparison of answers from Saturated and Emerging Markets regarding future product strategy.

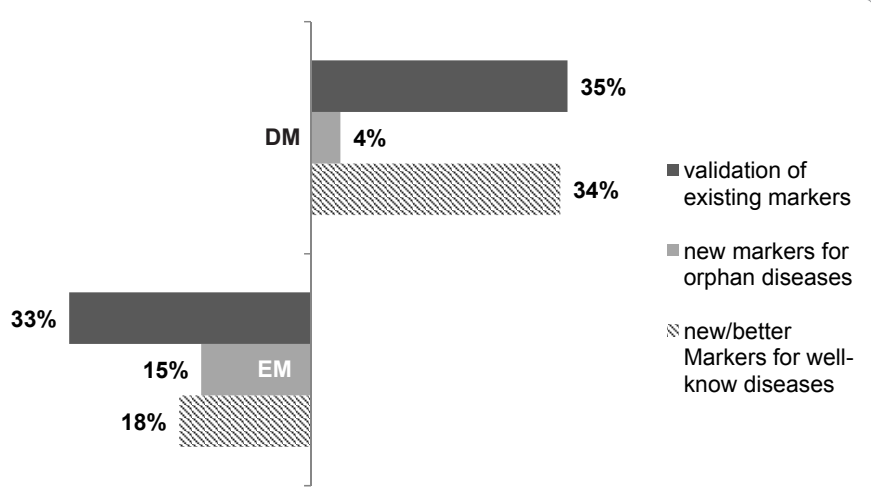

Figure 6: Customer`s expectations regarding product development.(\% rounded).

existing markers (33.8\%, $\mathrm{N}=78$ out of 231 ). A fairly comparable amount of physicians supported this strategy in DM $(35.1 \%, \mathrm{~N}=27$ out of 77$)$ and EM (33.1\%, N=51 out of 154). Major differences between both markets could be identified regarding the need for better diagnostic markers for well-known diseases.

$33.8 \%(\mathrm{~N}=26$ out of 77$)$ of physicians in DM saw a high unmet need for such development, while only $17.5 \%(\mathrm{~N}=27$ out of 154$)$ of the medical community in EM agreed with this statement $(\Delta=16.2 \%$ with $\mathrm{p}=0.009$ ). Completely contrary answers were derived for the question of whether investment should be increased for the development of markers for orphan/neglected diseases. Here, $14.9 \%(\mathrm{~N}=23$ out of 154$)$ of physicians in EM indicated a strong interest for a more focused approach in the diagnostic industry, whereas only $3.9 \%(\mathrm{~N}=3$ out of $77)$ of physicians in DM saw this as a medical necessity $(\Delta=11.0 \%$ with $\mathrm{p}=0.002$ ) (Figure 6).

Regarding the development of electronic devices to improve processing and distribution of data (such as Apps and devices for selfmanagement), comparable interest has been indicated by both markets (EM: $7.8 \%, \mathrm{~N}=12$ out of $154, \mathrm{DM}: 7.8 \%, \mathrm{~N}=6$ out of 77 ).

Slightly more $(\Delta=7.1 \%$ with $\mathrm{p}=0.21)$ relevance for the development of companion diagnostics has been stated from physicians of EM (26.6\%, N=41 out of 154$)$ than from DM-physicians $(19.5 \%, \mathrm{~N}=15$ out of 77). This product strategy, however, remained the second most frequently chosen option; particularly in the low-mid income economy India.

Key message: Physicians of both markets expressed their belief for the necessity to develop treatment algorithms for existing markers. Physicians in DM demand better markers for well known-diseases.

\section{Discussion}

This paper addresses the current world-view of a small randomly selected group of physicians from eight different countries and three different economic prosperities on the Medical Value strategy. The survey had a high return rate of $96.3 \%(\mathrm{~N}=231$ out of 240$)$. Because the origin of the questions was blinded for participating physicians, a bias of answers concerning the vendor's reputation could be excluded. The current investigation at least provides 4 important results.

1. There is a large demand in all markets for reliable treatment algorithms that accompany new product developments. Clinical trials have a strong potential to enhance the confidence of physicians to apply assays in their clinical practice. Confidence for application of diagnostic assays may erode when the consequence of a test result 
Citation: Schäfer H Hendrik, Filser Ludwig, Rohr Ulrich P, Laubender Ruediger P, Dieterle Thomas, Maitland Roger, Zaugg Christian E (2015) Medical Value as a New Strategy to Increase Corporate Viability: Market Chances and Limitations in the Diagnostic Industry. J Entrepren Organiz Manag 4: 131. doi:10.4172/2169-026X.1000131

Page 7 of 8

cannot confidently be translated into clinical decisions or actions. Potentially this concern is an explanation why technical excellence and preciseness is not ranked as the most critical parameter for future product development in both markets. Sensitivity improvements (e.g. in cardiac troponins or increasing the sensitivity of HIV detection) without providing the means for a better patient management may limit the value of assays only to "technical innovation". This finding highlights the importance of understanding the connection between the psychological concept of "confidence" concerning a given product/ procedure and the willingness to apply it.

2. The MV concept is not limited to novel markers. A high number of physicians believed that the focus for development should be shifted towards exploiting the diagnostic potential of existing markers in both DM and EM. Given different economic prosperities physicians from DM saw a higher need to develop better diagnostic markers for wellknown diseases. This result displays the gap between the medical care standard of SM and EM, where the potential of existing markers has not been utilized yet.

3. The level of economic prosperity has an impact on the willingness to pay for medical innovation. In the light of increasing financial pressure, the most cost-effective diagnostic/therapeutic option has given higher priority in DM compared to EM. This is rooted in different market environments. Based on global scenarios the health economic outlook of the OECD [29] predicts that the majority of EM will create health care costs that positively correlate with their GDP development [29] and therefore, are likely to accept also costly innovations that add value to an individualized treatment approach. $\mathrm{DM}$, on the other hand, is likely to experience financial cutbacks on their health care systems and will navigate towards society-focused, rather than individually focused systems. This theory is in line with the answers from the current survey, in which the majority of DM physicians believed that the whole society must profit from solutions exceeding current gold-standards.

4. There is a different perception of the term "Gold Standard", which can be fundamentally different depending on the economic environment. This might be rooted in the fact that the term, historically taken over from economists, has no clear definition. Occuring 1955 for the first time and used in its current sense by Rudd since 1979 [30] "Gold Standard" describes a method/procedure that is widely recognized as the best available. With more than 10.000 publications since 1995 [31[ the term is now widely accepted in the medical literature [32]. Even though, in our investigation the majority of physicians comprehend "Gold standard" as previously defined, a main concern of EM was the equitable access of all patients to well-performing diagnostic tools. This can be seen as a "Gold Standard" of a higher abstraction level. Like in Maslow`s hierarchy of needs [33] a primary unmet need has to be met before the next higher need emerges. Equitable access to diagnostic tools speaks to the primary need of cost efficient high-volume testing efficiency.

In DM the situation is different as the primary need is generally met and the current "Gold Standard" can be challenged. This finding displays how differently the term "Gold Standard" is used. It is important to acknowledge that a "Gold Standard" is subjective and, despite oriented on contemporary guideline recommendation, not generalizable.

\section{Limitations of MV and Further Research}

The "added MV component" in terms of a biomarker algorithm is unique and product-specific. Proposals for clinical decision-making have to be established in derivation cohorts of clinical trials, and tested in validation cohorts. Thus, biomarker algorithms, leading to clinical decisions are not interchangeable and thus unique to the investigated biomarker (e.g. Troponin T, Troponin I). This fact cannot accommodate the request of customers for global data comparability but naturally prevents "product substitution" through "aut-idem" products and services. Product uniqueness is a "condition sine qua non" to remain a competitive advantage. The contradiction between customers' demand and entrepreneurial necessity displays the limits of the MV concept and should be investigated in further studies. Especially more research is required to assess how the concern about data-comparability can be addressed to increase social value without destroying shareholder value.

\section{Conclusions}

Added value, based on an improvement of patient flows (diagnostic algorithms) is a valuable product strategy in DM but less applicable in EM. While customers in EM still see technical refinement of test systems as important, customers of DM emphasize the value component of accompanying algorithms. Especially in DM, attention must be paid not to destroy value through exclusive focus on technical improvement while neglecting the applicability and utility of refinement. Our results also show that the impact of MV on society (release of health care resources) has not been fully understood by customers yet.

More cost-effectiveness studies are needed, whose current lack increases the risk of uninformed decision making by policy makers, government officials and payers as important stakeholder groups [34].

Our results emphasize a likelihood of revenue decline for the diagnostic industry, when the MV concept is not given attention. The high desire for the "value" component in both markets is particularly emphasized through the demand for the validation of existing diagnostic tests.

Diagnostics must support physicians towards more straightforward decision-making. If this requirement is fulfilled, not only MV but also societal value is created. MV is a design strategy to insure the long-term stability of Roche's competitive advantage through organizational innovation by addressing the needs of society and patients.

\section{References}

1. Smith KM, Kates JA (1996) Regulatory hurdles in bringing an in vitro diagnostic device to market. Clinical Chemistry 42: 1556-1557.

2. Salop SC (1979) Monopolistic Competition with Outside Goods. Bell Journal of Economics 10: 141-156.

3. Koberg CS (2003) An empirical test of environmental, organizational and process factors affecting incremental and radical innovation. The Journal of High Technology Management Research 14: 21-45.

4. Singh JV (1986) Performance, Slack, and Risk Taking In Organizationa Decision Making. Academy of Management Journal Academy of Management Journal 29: 562-585.

5. Schumpeter JA (1976) Capitalism, Socialism and Democracy. George Allen and Unwin Publishers, Australia.

6. Dixit AKS, Joseph E (1977) Monopolistic Competition and Optimum Product Diversity. American Economic Review 67: 297-308.

7. Aghion P, Bloom N, Blundell R, Griffith R, Howitt P (2005) Competition and Innovation: an Inverted-U Relationship. The Quarterly Journal of Economics 120: 701-728.

8. Travis P, Bennett S, Haines A, Pang T, Bhutta Z, et al. (2004) Overcoming 
Citation: Schäfer H Hendrik, Filser Ludwig, Rohr Ulrich P, Laubender Ruediger P, Dieterle Thomas, Maitland Roger, Zaugg Christian E (2015) Medical Value as a New Strategy to Increase Corporate Viability: Market Chances and Limitations in the Diagnostic Industry. J Entrepren Organiz Manag 4: 131. doi:10.4172/2169-026X.1000131

Page 8 of 8

health-systems constraints to achieve the Millennium Development Goals. Lancet. Public Health 364: 900-906.

9. Ruyter KD, Wetzels M, Lemmink J, Mattason J (1997) The dynamics of the service delivery process: a value-based approach. International Journal of Research in Marketing 14: 231-243.

10. Desiere F, Gutjahr TS, Rohr UP (2013) Developing companion diagnostics for delivering personalised medicine: opportunities and challenges. Drug Discovery Today: Therapeutic Strategies.

11. Jaques H (2013) NICE guideline on hypertension. European Heart Journal 34 406-408.

12. Fischer KE, Stargardt T (2014) Early Benefit Assessment of Pharmaceuticals in Germany: Manufacturers' Expectations versus the Federal Joint Committee's Decisions. Med Decis Making 34: 1030-1047.

13. Eichler HG, Kong SX, Gerth WC, Mavros P, Jonsson B (2004) Use of costeffectiveness analysis in health-care resource allocation decision-making: how are cost-effectiveness thresholds expected to emerge? Value in health. The Journal of the International Society for Pharmacoeconomics and Outcomes Research 7: 518-528.

14. WHO (World Health Organization) Burden of Disease.

15. The World Bank: Health expenditure per capita, 2014.

16. Harvard School of Public Health: The Global Economic Burden of NonCommunicable Diseases: A report by theWorld Economic Forum and the Harvard School of Public Health.

17. Miller I, Ashton-Chess J, Spolders H, Fert V, Ferrara J, et al. (2011) Market access challenges in the EU for high medical value diagnostic tests. Personalized Medicine 8: 137-148.

18. Porter ME (2010) What is value in health care? N Engl J Med 363: 2477-81.

19. Porter ME, Teisberg EO (2006) Redefining Health Care: Creating Value-Based Competition on Results. Harvard Business School Press, Boston.

20. Deverka PA (2009) Pharmacogenomics, evidence, and the role of payers. Public Health Genomics 12: 149-157.

21. Woolf SH, Grol R, Hutchinson A, Eccles M, Grimshaw J (1999) Clinical guidelines: potential benefits, limitations, and harms of clinical guidelines. BMJ 318: 527-530.
22. Jeremias A, Gibson CM (2005) Narrative review: alternative causes for elevated cardiac troponin levels when acute coronary syndromes are excluded. Annals of Internal Medicine 142: 786-791.

23. Pearson SD, Goldman L, Orav EJ, Guadagnoli E, Garcia TB, et al. (1995) Triage decisions for emergency department patients with chest pain: do physicians' risk attitudes make the difference?. Journal of general Internal Medicine 10: 557-564.

24. Katz DA, Williams GC, Brown RL, Aufderheide TP, Bogner M, et al. (2005) Emergency physicians' fear of malpractice in evaluating patients with possible acute cardiac ischemia. Annals of Emergency Medicine 46: 525-533.

25. Hwang U, Baumlin K, Berman J, Chawla NK, Handel DA, et al. (2010) Emergency department patient volume and troponin laboratory turnaround time. Academic Emergency Medicine 17: 501-507.

26. Tubaro M (2011) Use of high-sensitivity troponins in clinical practice: is it a solution or or a problem? Troponin sensitivity results in safety and timeliness. G Ital Cardiol (Rome) 12: 492-496.

27. Pai NP, Marina K (2008) Are we Ready for Home-based, Self-testing for HIV? Future HIV Therapy 2: 515-520.

28. Mueller M, Biener M, Vafaie M, Doerr S, Keller T, et al. (2012) Absolute and relative kinetic changes of high-sensitivity cardiac troponin $\mathrm{T}$ in acute coronary syndrome and in patients with increased troponin in the absence of acute coronary syndrome. Clinical Chemistry 58: 209-218.

29. What future for health spending? OECD (2013) OECD Economics Department Policy Notes.

30. Rudd $P$ (1979) In search of the gold standard for compliance measurement. Arch Intern Med 139: 627-628.

31. Claassen JA (2005) Gold standard, not golden standard. Ned Tijdschr Geneeskd 149: 2937.

32. Versi E (1992) Gold standard is an appropriate term. BMJ 305: 187.

33. Rakowski N (2008) Maslow's Hierarchy of Needs Model - the Difference of the Chinese and the Western Pyramid on the Example of Purchasing Luxurious Products. GRIN Verlag, Germany.

34. Parkinson DR, Ziegler J (2009) Educating for personalized medicine: a perspective from oncology. Clinical Pharmacology and Therapeutics 86: 23-25. 